\title{
Role of Agricultural Infrastructure and Climate Change on Agricultural Efficiency in Uttar Pradesh: A Panel Data Analysis
}

\author{
Sanjeev Kumar* and Devna Joshi \\ Department of Economics, University of Lucknow, Lucknow, Uttar Pradesh, India \\ *Corresponding author: sanjeeveco@gmail.com
}

\begin{abstract}
The present research paper has examined the process of agricultural infrastructure, climate change and agricultural efficiency in Uttar Pradesh at district as well as regional level from 2004-05 to 2015-16. Agricultural Infrastructure Indices (AII) have been estimated through Principal Component Analysis (PCA) by taking eight variables related to agricultural infrastructure to identify the disparities within the district as well as regional level. Agricultural Efficiency Index (AEI) has also been estimated to identify the trends of agricultural efficiency and panel data regression analysis was employed to analyze the determinants of agricultural efficiency index at disaggregate level of Uttar Pradesh. The values of agricultural infrastructure index (AII) confirmed that rural infrastructure has been enhanced in all the districts and regions from 2004-05 to 2015-16 with some fluctuations. Moreover, the results of agricultural efficiency revealed that the pattern of efficiency at district and regional level has undergone a significant shift towards a higher level during the study period. However, this shift was not uniformly distributed across the districts/regions. The regional level result of UP indicated that WUP recorded highest AEI and AII followed by CUP, EUP and Bundelkhand respectively. The results of Random Effect Model confirmed that agriculture infrastructure index (AII); gross sown area per tractor, percentage of loan for agriculture and rainfall variability have been found the significant determinants of agriculture efficiency, while per hectare fertilizer, maximum temperature and minimum temperature have established insignificant relationship with agricultural efficiency. This paper suggests policy support in terms of enhanced agriculture infrastructure, mitigation of vulnerable climatic factors, appropriate use of agriculture inputs and suitable technology to achieve higher degree of agricultural efficiency and also generate higher income for farmers. Furthermore, the use of technological inventions by public--private participation in the cultivation methods of various crops needs to be encouraged for achieving agriculture efficiency at disaggregate level.
\end{abstract}

Keywords: Agricultural efficiency, agricultural infrastructure, Climate Change, random effect model

In the recent economic environment, efficiency and competitiveness ought to be the basis of every development strategy of agriculture. These cues are very pertinent in the context of farmers of developing countries, particularly India, where the size of land holding primarily belongs to the small and marginal farmers and traditional cropping pattern with low productivity remains a grave concern. Moreover, non-viability of agriculture sector in provision of subsistence income to farmers as well as employment opportunities to the rural population only adds to the problems. Agriculture efficiency is thereby a precursor of agriculture development in India because it is directly related to the productivity of the agriculture sector that can aide in combating such issues.

Agriculture is invariably one of the quintessential cornerstones of economic development in Uttar Pradesh. This can be corroborated by its significant contribution towards gross state domestic product (GSDP), dependence of majority of the population for their livelihoods and attainment of self sufficiency in food production. In terms of food grain production in 2016-17, Uttar Pradesh held the top position among all the states in India and accounted for about 17.83 per cent share in the country's total food 
grain production. In case of dominant food grain crops such as rice, wheat, maize, millet, gram, pea and lentils as well, the state is the major producer while the production of vegetables was found $28,226.19$ thousand tonnes in 2017-18, making the state the largest producer of vegetables in India (Agricultural Statistics at a Glance, 2017).

Khandker (1989) conducted a study in India and found that the impact of government investment on roads had established a positive relationship with agriculture output, rural non-farm employment and agricultural wages. Government spending on investments for enhancing the productivity or efficiency through research \& development, irrigation facilities, and agricultural infrastructure in rural areas of India contributed to reductions in rural poverty and contributed towards the growth in productivity of agriculture sector. The leading impacts on poverty reduction and enlargement in agricultural productivity are brought through roads facilities and research \& development. Investment in irrigation only has a modest impact on agricultural productivity and poverty reduction in India (Fan et al. 2000). In this direction, some studies are available both at the international as well as in the Indian context of agriculture (Spencer, 1994; Kurian, 2001, Chand, 2001; Thorat et al. 2003; Modi, 2005) that have pointed out the significance of economic infrastructure to boost up agriculture productivity and at the same time provide a strategy for rural development.

Even though, a lot of studies have tried to examine the link between urban infrastructure and economic development in India, only a few of them have analysed the progress and economic efforts of rural infrastructure (Binswanger et al. 1993; Bhatia, 1999; Zhang et al. 2001; and Nayak, 2008 \& 2014). Out of these studies, Bhatia (1999) addressed the inter-state disparity of India in rural infrastructure, which has attempted to build a composite index though Principal component analysis (PCA) of rural infrastructure at state level and examined the relationship between rural infrastructure development and agriculture growth. Moreover, climate change has wide ranging impacts on the rural economy including agricultural productivity, revenues of the farm household and asset values. Also, it affects the agricultural infrastructure through the change in water sources available for agriculture. Mellor (1976) highlighted that infrastructure plays a strategic role in producing large multiplier effects in agricultural growth. It is estimated by World Bank (1997) that across the world, 15 per cent of crop produce is lost between farm gate and consumer because of poor roads and inappropriate storage facilities. Parikh (1999) in his development report has also placed UP in the deficient category in terms of electricity, roads, storage, credit facilities, etc.

UP made a lot of progress in agriculture sector since independence, but still it is facing regional disparities in production and productivity within the state and it has lower productivity as compared to other developed states in India. However, there is a tremendous scope to boost up the growth of agricultural sector of UP through enhancing agricultural productivity or efficiency. Agricultural infrastructure, climatic factors and availability of agricultural inputs are the main drivers to boost up agricultural productivity and agricultural efficiency.

However, there is very scarce literature with regards to empirical substantiation of impact of agriculture infrastructure and other factors on agricultural efficiency in Uttar Pradesh at district level and hence exploring proper drivers of agricultural efficiency is of paramount importance to better targeting and restructuring of government policies. Against this backdrop, the present paper has the following specific objectives:

- To examine the trends of agriculture efficiency index (AEI) and agriculture infrastructure index (AII) at the district and regional level in Uttar Pradesh.

- To allocate ranks and map the same at district level based on their performances with respect to the indexes generated.

- To identify the determinants of agriculture efficiency in terms of agriculture infrastructure, climatic factors and agricultural inputs.

- To suggest policy implications in order to augment the role of agriculture infrastructure and agricultural efficiency on agriculture growth keeping the view of government commitment of doubling farm incomes by 2022 .

\section{Conceptual Framework}

The research paper via agricultural infrastructure 
variable has tried to identify three broad parameters viz. economic infrastructure in terms of irrigation, electricity, transport and telecommunication; institutional infrastructure in terms of agriculture market and primary agriculture cooperative societies and social infrastructure in terms of education and health. These parameters of agricultural infrastructure contribute to agricultural growth and its efficiency, either directly or indirectly. Agricultural development or its efficiency is a multi-dimensional phenomenon where different factors and conditions should work together to achieve the potential level of agriculture output. The agriculture efficiency is influenced by various factors such as climatic factors, development of agricultural infrastructure, technological improvements, agricultural inputs and economic policies of the government as shown in Fig. 1.

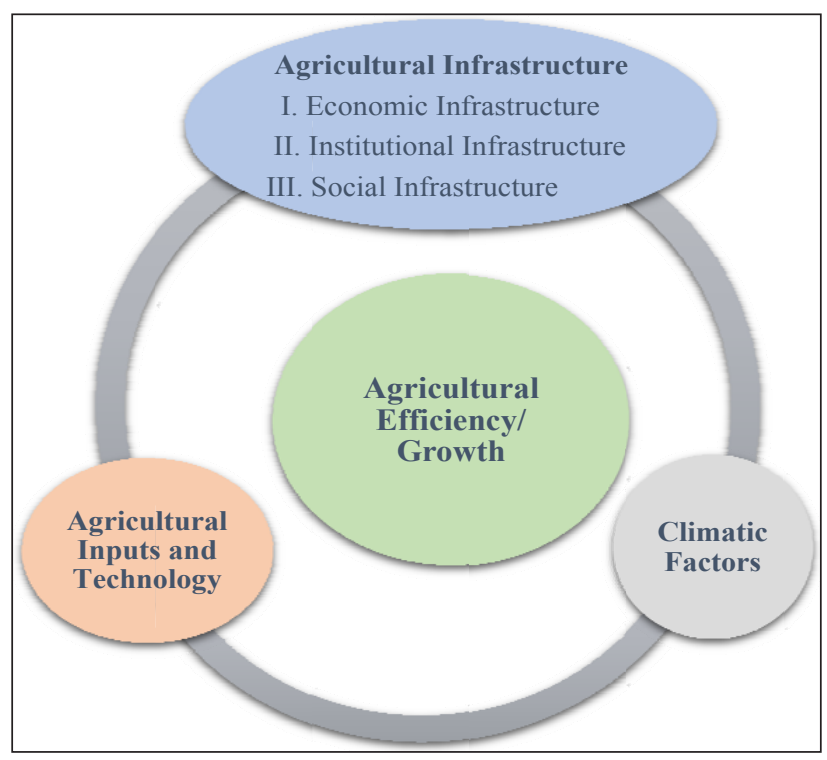

Fig. 1: A Diagrammatic Representation of the Relationship between Agriculture Efficiency and Its drivers

Source: Author's Diagram.

The economic and institutional infrastructure, i.e., the basic services and facilities available to the farming population, has been directly related to agricultural efficiency and the development of social infrastructure becomes important as it contributes to the development processes of agriculture indirectly. Social infrastructure plays a significant role in upgrading the skill formation of the farmers to achieve greater operational accuracy in accessing and utilization of services (Acharya et al. 1992). Agricultural infrastructure with better input and machinery of agriculture contributes to enhance the agricultural growth as well as agricultural efficiency and at the same time, it is proposed that, these facilities and services of the public need to be utilized to their fullest potential to gain from these investments and reach better level of agricultural productivity and efficiency. Climatic factors and government policies have been taken as exogenous factors of agricultural efficiency.

\section{Database and Methodology}

The database for the present study was taken from various secondary data sources viz. Directorate of Economics \& Statistics, Government of Uttar Pradesh (UPDES), Land Use Statistics (LUS) prepared by DACNET, District Wise Development Indicators of Uttar Pradesh and Statistical Abstract of UP, Economics \& Statistics Division, State Planning Institute Planning Department, Government of Uttar Pradesh.

The methodology of research paper has been divided into three sub-sections. The first sub-section elaborates the construction of the Agriculture Infrastructure Index (AII), the second sub-section spells out the estimation of the Agricultural Efficiency Index (AEI) while the last sub-section discusses the regression model for panel data analysis.

\section{Construction of Agriculture Infrastructure Index (AII)}

Agriculture Infrastructure Index (AII) includes three broad parameters i.e. economic, institutional and social infrastructure. Further, these three broad parameters of infrastructure were divided into eight indicators of infrastructure. These indicators have been selected through the Principal Component Analysis (PCA) on the basis of Eigen value criterion. The list of the parameters and indicators are given in the Table 1.

Normalisation of variables: In order to arrive at standardized values of indicators of agriculture infrastructure, the method of normalization was used. The indicators were normalised using a minimax normalisation method. The mini-max method of each indicator was transformed as follows:

$$
I_{q d}^{t}=\frac{X_{q d}^{t}-\operatorname{Min}_{d}\left(X_{q}^{t}\right)}{\operatorname{Max}_{d}\left(X_{q}^{t}\right)-\operatorname{Min}_{d}\left(x_{q}^{t}\right)}
$$


Table 1: Indicators of Agriculture Infrastructure Index (AII)

\begin{tabular}{|c|c|c|}
\hline $\begin{array}{l}\text { Infrastructure } \\
\text { Parameters }\end{array}$ & $\begin{array}{l}\text { Indicators of } \\
\text { infrastructure }\end{array}$ & Indicator Description \\
\hline \multirow{2}{*}{$\begin{array}{l}\text { Economic/ Physical } \\
\text { Infrastructure }\end{array}$} & Irrigation & Ratio of Net irrigated area to net sown area in the district \\
\hline & Transport & $\begin{array}{l}\text { Road length per thousand square kilometers (Length of roads per } 1000 \\
\text { square } \mathrm{km} \text { of area) }\end{array}$ \\
\hline \multirow{2}{*}{ Social Infrastructure } & Education & $\begin{array}{l}\text { Number of schools per lakh population; primary and junior basic school } \\
\text { of the district }\end{array}$ \\
\hline & Health & $\begin{array}{l}\text { Number of hospitals, dispensaries and primary health centers per lakh } \\
\text { population of the district }\end{array}$ \\
\hline $\begin{array}{l}\text { Institutional } \\
\text { Infrastructure }\end{array}$ & Markets & $\begin{array}{l}\text { Number of agriculture production societies (in lakhs) in per hectare (Net } \\
\text { Sown Area) (Agriculture Mandi) }\end{array}$ \\
\hline
\end{tabular}

Sources: Authors table.

Where $\operatorname{Max}_{d}\left(X_{q}^{t}\right)$ and $-\operatorname{Min}_{d}\left(X_{q}^{t}\right)$ are the maximum and the minimum values of $X_{q d}{ }^{t}$ across all the districts $d$ of Uttar Pradesh at time $t$. In this way the normalized indicators $I_{q d}{ }^{t}$ have values lying between 0 and 1 . Thus, the higher the values of $I_{q d}{ }^{t}$; the higher the district achievement in indicator $q$.

As earlier stated, PCA and factor analysis were used in order to generate the weights of agricultural infrastructure. This facilitated to construct weights representing the information content of individual indicators without reducing the number of indicators (OECD, 2008). Finally, the following equation was used in order to aggregate the outcomes and arrive at the Agriculture Infrastructure Index (AII) for the all seventy districts and four administrative regions of Uttar Pradesh from the year 2004-05 to 2015-16;

$$
A I I=\sum_{q=1}^{Q} w_{q} I_{q d}
$$

With $\sum_{q=1}^{Q} w_{q}=1$ and $0 \leq w_{q} \leq 1$, for all $q=1,2 \ldots \ldots . Q$ and $d=1,2 \ldots \ldots . .70$

\section{Estimation of Agricultural Efficiency Index (AEI)}

The method of measuring agricultural efficiency has been given by several researchers such as Kendal (1939), Shafi (1960), Khusro (1964), Sharma (1965), Bhatia (1967) and Jasbir Singh (1979). In this study Bhatia's method is applied to measure agricultural efficiency. The Measurement of agricultural efficiency as output per unit area is based on acreyields of crops and a measure for it was evolved by Kendal. According to Bhatia (1967) agricultural efficiency (AE) may be regarded as the aggregate performance of various crops expressed through their output per hectare/ acre but each crop would contribute proportionate to its share of crop land in the cropping pattern. The AEI was calculated for the state of Uttar Pradesh at district level for a total of 14 crops viz. rice, wheat, bajra, jowar, barley maize, arhar, gram, masoor, peas, rapeseed, til, potato, and sugarcane as these constituted more than 97 per cent of the total area under cultivation in Uttar Pradesh from 2004-05 to 2015-16.

The productivity/yield of selected crops in the component areal units were expressed as a percentage of the corresponding average productivity/ yield for the entire region to obtain indexes of productivity/ yield efficiency relative to the performance of the crop in the entire selected region. A weighted average of the productivity/ yield efficiency of all 14 selected crops in a component areal unit, where the weights are proportionate to the share of area devoted to each crop, would give a measure of the agricultural efficiency (AE) of the component areal unit relative to the entire region of the study (Bhatia, 1967). This can be expressed as:

$$
I_{y a}=\frac{Y_{c}}{Y_{r}} \times 100
$$


Where, $I_{y a}$ is the productivity/ yield index, $Y_{c}$ is the yield of crop in the concerned district, and $Y_{r}$ yield of crop a in the entire state/ region. Further, the Agricultural Efficiency Index (AEI) is estimated as follows;

$$
A E I_{i}=\frac{I_{y a} \times C_{a}+I_{y b} \times C_{b}+\ldots \ldots+I_{y n} \times C_{n}}{\sum_{i=a}^{n} C}
$$

Where, $A E I_{i}$ is the agricultural efficiency index, $I_{y d^{\prime}}$ $I_{y b^{\prime}}, \ldots, I_{y n^{\prime}}$ are the productivity/ yield indexes of various crops, and $C_{a^{\prime}} C_{b} \ldots, C n$, are percentages of crop area under the different selected crops.

\section{Panel Data Regression Model}

There is a very close relationship between agricultural efficiency and agricultural development. Agricultural efficiency depends on of several factors viz. agricultural infrastructure, technology, climate and inputs. The collective effect of these factors manifests itself in productivity as well as agricultural efficiency. The agricultural efficiency obviously implies that maximum return is obtained from land under the given conditions. Apart from measuring the Agricultural Efficiency Index (AEI) and Agriculture Infrastructure Index (AII) at the district level of Uttar Pradesh, the determinants of AEI at the district level were also examined in the present paper.

There are broadly three methods of panel data regression model viz. Pooled Ordinary Least Square Regression Model (Constant Coefficient Model), Fixed Effect Model (FEM) and Random Effect Model (REM). In pooled regression estimation, it is assumed that coefficients across time and crosssection remain the same. The major problem with this model is that it does not discriminate between the various entities or panels (districts) that we have in the model. For the selection of best model between FEM and REM, Hausman specification test was employed to check suitability of the method.

The data consists of 70 districts of UP (Total observation $=70 \times 12=840$ observations) with a 12 year time span i.e. from 2004-05 to 2015-16 for 70 districts of UP. For the purposes of the present study an attempt was made to find an association of Agricultural Efficiency Index (AEI as dependent variable) with agriculture infrastructure index (AII); gross sown area per tractor (GSATR), percentage of loan distribution of agriculture sector in total loan distribution (PAGLD), per hectare fertilizer, (PHFERT), rainfall variability (RAINV); maximum temperature (MAXT), minimum temperature (MINT) (independent variables) along with dummy variables for regions, i.e., Bundelkhand (BUL), Eastern Uttar Pradesh (EUP), Central Uttar Pradesh (CUP) and Western Uttar Pradesh (WUP). The fixed effects model (FEM) and the random effects model (REM) was used for further analysis.

\section{Fixed Effect Model (FEM)}

To take into account the individuality of each state (cross-sectional unit), intercept is varied by using dummy variable for fixed effects. Fixed effect models for panel data (intercept or individual) are given by equation:

$$
\begin{aligned}
& A E I_{i t}=\beta_{1}+\beta_{2} A_{i t}+\beta_{3} \text { GSATR }_{i t}+\beta_{4} \text { PAGLD }_{i t}+\beta_{5} \\
& \text { PHFERT }_{i t}+\beta_{7} \text { MAXT }_{i t}+\beta_{8} \text { MINT }_{i t}+D_{2-} \text { EUP }+ \\
& D_{-3} \mathrm{CUP}+\mathrm{D}_{-4} \mathrm{WUP}+u_{i t}
\end{aligned}
$$

Here, $\mathrm{i}=1,2,3,-----70$ [cross section (districts)] and $\mathrm{t}$ $=1,2,3------12$ [time period (years)]

$\beta_{1}, D_{2}, D_{3}$ and $D_{4}$ are dummy varibles for regions and $u_{i t}$ stochastic error term

\section{Random Effect Model (REM)}

In the random effect model, it is assumed that the individual specific coefficient $\beta_{1 i}$ is fixed for each time-invariant. In the random effect model, it is assumed that $\beta_{1 i}$ is a random variable with a mean value of $\beta_{i}$ (no $i$ subscript here) and the intercept of any cross-section unit is expressed as in following equation;

$$
\beta_{1 i}=\beta_{1}+\varepsilon_{i}
$$

Where $\varepsilon_{i}$ is a random error term with mean ' 0 ' and variance $\sigma_{\varepsilon}^{2}$.

Therefore, random effect model for panel data can be written as by the equation $(\mathrm{V})$;

$$
\begin{gathered}
\text { SID }_{i t}=\beta_{1}+\beta_{2} \text { AII }_{i t}+\beta_{3} \text { GSATR }_{i t}+\beta_{4} \text { PAGLD }_{i t}+\beta_{5} \\
\text { PHFERT } \\
D_{-3} \text { CUP }+\beta_{7} \text { MAXT }_{i t}+\beta_{8} M \text { MINT }++w_{i t}+D_{-2} E U P+
\end{gathered}
$$

Where; $w_{i t}=\varepsilon_{i}+u_{i t}$

The composite error term $w_{i t}$ has two components; $\varepsilon_{i}$ represent the cross-section or individual-specific 
error component and $u_{i t}$ represents combined time series and cross-section error component.

\section{Hausman Specification Test: Which model is suitable, i.e., FEM or REM}

Hausman specification test (1978) was used to select appropriate model between fixed effect model (FEM) and random effect model (REM). It is designed to detect violation of the random effects model assumption that the explanatory variables are orthogonal to the unit effects. If there is no correlation between the independent variables and the unit effects, then estimates of ' $\beta$ ' in the FEM $\left(\hat{\beta}_{F E}\right)$ should be similar to estimates of ' $\beta$ ' in the $\operatorname{REM}\left(\hat{\beta}_{R E}\right)$. The Hausman test statistic ' $\mathrm{H}$ ' is given by equation;

$$
H=\left(\hat{\beta}_{R E}-\hat{\beta}_{F E}\right)^{\prime}\left[\operatorname{Var}\left(\hat{\beta}_{F E}\right)-\operatorname{Var}\left(\hat{\beta}_{R E}\right)\right]^{-1}\left(\hat{\beta}_{R E}-\hat{\beta}_{F E}\right)
$$

\section{RESULTS AND DISCUSSION}

This section of the paper has been divided into three sub-sections. The first sub-section analyses the trends and rank allocations of the Agriculture Infrastructure Index (AII) at district and regional level in UP, the second sub-section explains the trends and rank allocations of the Agricultural Efficiency Index (AEI) at district and regional, while the last sub-section discusses the panel data regression result.

\section{Trends of Agricultural Infrastructure (AII)}

The trends of Agricultural Infrastructure Index (AII) along with rank allocation at district level for Uttar Pradesh are presented in Table 2. It shows that the districts like Ghaziabad, Lucknow, Meerut, Haathras, Muzzafarnagar, Baghpat, Saharanpur, Kanpur nagar, G. B. Nagar and Aligarh have fared quite well and attained the top ranks in terms of Agricultural Infrastructure Index (AII) in the year 2004-05, while, S.R. Nagar, Hamirpur, Bahraich,

Mahoba, Siddharth Nagar, Basti, Sonbhadra, Gonda, Chitrakoot, and Balrampur slipped down and figured among the lowest ten districts in terms of AII rank during the same period. The rest of the districts fell between them. On the other hand, slight variations in the AII rank were observed in the year 2015-16 across the districts of Uttar Pradesh. G.B. Nagar, Meerut, Ghaziabad, Lucknow, Mainpuri, Jhansi, Faizabad, Kannauj, Lalitpur, and Etah however, were the top rankers in terms of AII in the year 2015-16 whereas, the districts like Basti, Bahraich, Banda, Shravasti, Mahoba, S.K. Nagar, Chitrakoot, S.R. Nagar, Sonbhadra and Balrampur attained the lowest rank during the year 2015-16 at state level. Overall it was observed that districts such as Allahabad, Auraiya, Azamgarh, Bahraich, Barabanki, Basti, Bijnor, Bulandshahr, Chitrakoot, Etah, Etawah, Faizabad, Farukkhabad, Fatehpur, Firozabad, GB Nagar, Gonda, Hamirpur, Hardoi, J.P. Nagar, Jhansi, Kannauj, Kanpur Dehat, Kushinagar, Lalitpur, Mainpuri, Mau, Meerut, Mirzapur, Moradabad, Raebarelli, Rampur, Siddhartha nagar, Sitapur, Sultanpur and Unnao revealed a relatively improved rank in the Agriculture Infrastructure Index to the other districts indicating a direct relationship between infrastructure and agricultural productivity.

Across administrative regions, it was found that the agricultural infrastructure rank of Bundelkhand ascended from $4^{\text {th }}$ in 2004-05 to $3^{\text {rd }}$ in $2015-16$ while the rank of eastern region slipped from $3^{\text {rd }}$ in 2004-05 to $4^{\text {th }}$ in 2015-16 at state level. On the other hand, in the central and western regions no change was observed in the respective ranks in the year 2004-05 and 2015-16. From the analysis, it is inferred that Bundelkhand has performed relatively better in terms of improvement in rank as compared to the other administrative regions.

However, comparing by values, it was found that the all the regions have experienced an improvement with respect to the base year. Western UP particularly has outnumbered all the regions followed by Central UP. The performance of Eastern region has relatively deteriorated in 2015-16 when compared with the year 2004-05. This is followed by district-wise comparison of values of agriculture infrastructural index (AII) levels through Map 1 at time point 2004-05 and 2015-16.

The district wise agriculture infrastructure index levels during the study period can be divided into three categories, namely, low: $<0.35$, moderate: ( 0.35 to 0.39 ) and highest: $>0.39$. The following map shows that the agriculture infrastructure index has variations across all selected districts during the study period at the state level. It is a fact that there 
Table 2: Trends of Agricultural Infrastructure Index (AII) and Rank at District Level

\begin{tabular}{|c|c|c|c|c|c|c|c|c|c|}
\hline \multirow{2}{*}{ Districts } & \multicolumn{2}{|c|}{ AII Values } & \multicolumn{2}{|c|}{ AII Rank } & \multirow{2}{*}{ Districts } & \multicolumn{2}{|c|}{ AII Values } & \multicolumn{2}{|c|}{ AII Rank } \\
\hline & 2004-05 & 2015-16 & 2004-05 & 2015-16 & & 2004-05 & 2015-16 & 2004-05 & 2015-16 \\
\hline Agra & 0.33 & 0.40 & 17 & 21 & Jalaun & 0.29 & 0.36 & 29 & 43 \\
\hline Aligarh & 0.37 & 0.39 & 10 & 25 & Jaunpur & 0.25 & 0.34 & 49 & 55 \\
\hline Allahabad & 0.25 & 0.39 & 47 & 32 & Jhansi & 0.28 & 0.45 & 33 & 6 \\
\hline Amb. Nagar & 0.36 & 0.34 & 12 & 56 & Kannauj & 0.30 & 0.43 & 25 & 8 \\
\hline Auraiya & 0.25 & 0.39 & 46 & 31 & Kanpur Dehat & 0.24 & 0.34 & 50 & 49 \\
\hline Azamgarh & 0.23 & 0.38 & 57 & 36 & Kanpur Nagar & 0.38 & 0.40 & 8 & 19 \\
\hline Baghpat & 0.39 & 0.39 & 6 & 28 & Kaushambi & 0.28 & 0.34 & 31 & 52 \\
\hline Bahraich & 0.18 & 0.31 & 63 & 62 & Kheri & 0.23 & 0.32 & 58 & 60 \\
\hline Balia & 0.34 & 0.36 & 14 & 42 & Kushinagar & 0.23 & 0.35 & 55 & 47 \\
\hline Balrampur & 0.13 & 0.21 & 70 & 70 & Lalitpur & 0.26 & 0.43 & 43 & 9 \\
\hline Banda & 0.23 & 0.31 & 59 & 63 & Lucknow & 0.45 & 0.51 & 2 & 4 \\
\hline Barabanki & 0.26 & 0.38 & 41 & 35 & Maharajganj & 0.25 & 0.35 & 45 & 48 \\
\hline Bareilly & 0.31 & 0.39 & 20 & 30 & Mahoba & 0.17 & 0.29 & 64 & 65 \\
\hline Basti & 0.17 & 0.31 & 66 & 61 & Mainpuri & 0.34 & 0.46 & 15 & 5 \\
\hline Bijnor & 0.28 & 0.38 & 35 & 34 & Mathura & 0.36 & 0.40 & 11 & 23 \\
\hline Budaun & 0.35 & 0.37 & 13 & 38 & Mau & 0.26 & 0.40 & 44 & 24 \\
\hline Bulandshahr & 0.32 & 0.40 & 19 & 17 & Meerut & 0.43 & 0.52 & 3 & 2 \\
\hline Chandauli & 0.29 & 0.36 & 26 & 41 & Mirzapur & 0.22 & 0.34 & 60 & 53 \\
\hline Chitrakoot & 0.13 & 0.28 & 69 & 67 & Moradabad & 0.29 & 0.40 & 27 & 18 \\
\hline Deoria & 0.30 & 0.37 & 24 & 39 & Muzzafarnagar & 0.39 & 0.42 & 5 & 12 \\
\hline Etah & 0.27 & 0.43 & 40 & 10 & Pilibhit & 0.24 & 0.33 & 54 & 58 \\
\hline Etawah & 0.31 & 0.41 & 21 & 13 & Pratapgarh & 0.29 & 0.39 & 30 & 33 \\
\hline Faizabad & 0.26 & 0.44 & 42 & 7 & Raebarelli & 0.34 & 0.41 & 16 & 15 \\
\hline Farukkhabad & 0.28 & 0.41 & 36 & 16 & Rampur & 0.30 & 0.40 & 23 & 20 \\
\hline Fatehpur & 0.24 & 0.34 & 52 & 50 & Saharanpur & 0.39 & 0.39 & 7 & 27 \\
\hline Firozabad & 0.27 & 0.39 & 39 & 26 & SK Nagar & 0.23 & 0.29 & 56 & 66 \\
\hline Ghazipur & 0.25 & 0.34 & 48 & 54 & SR Nagar & 0.21 & 0.28 & 61 & 68 \\
\hline GB Nagar & 0.37 & 0.53 & 9 & 1 & Shahjahanpur & 0.31 & 0.35 & 22 & 45 \\
\hline Ghaziabad & 0.47 & 0.51 & 1 & 3 & Shravasti & 0.28 & 0.30 & 37 & 64 \\
\hline Gonda & 0.16 & 0.35 & 68 & 46 & Sidd.Nagar & 0.17 & 0.33 & 65 & 57 \\
\hline Gorakhpur & 0.28 & 0.36 & 34 & 40 & Sitapur & 0.24 & 0.35 & 53 & 44 \\
\hline Haathras & 0.41 & 0.39 & 4 & 29 & Sonbhadra & 0.16 & 0.26 & 67 & 69 \\
\hline Hamirpur & 0.20 & 0.32 & 62 & 59 & Sultanpur & 0.29 & 0.40 & 28 & 22 \\
\hline Hardoi & 0.24 & 0.41 & 51 & 14 & Unnao & 0.27 & 0.38 & 38 & 37 \\
\hline J.P. Nagar & 0.28 & 0.42 & 32 & 11 & Varansi & 0.33 & 0.34 & 18 & 51 \\
\hline \multicolumn{10}{|c|}{ Administrative Region-wise Ranking based on Agricultural Infrastructure Index } \\
\hline \multirow{2}{*}{ Regions } & \multicolumn{2}{|c|}{ AII Values } & \multicolumn{2}{|c|}{ AII Rank } & Regions & \multicolumn{2}{|c|}{ AII Values } & \multicolumn{2}{|c|}{ AII Rank } \\
\hline & 2004-05 & 2015-16 & 2004-05 & 2015-16 & Kegions & 2004-05 & 2015-16 & 2004-05 & 2015-16 \\
\hline Bundelkhand & 0.22 & 0.35 & 4 & 3 & Eastern UP & 0.25 & 0.34 & 3 & 4 \\
\hline Central UP & 0.29 & 0.39 & 2 & 2 & Western UP & 0.33 & 0.41 & 1 & 1 \\
\hline
\end{tabular}

Sources: Authors Calculations based on UPDES. 

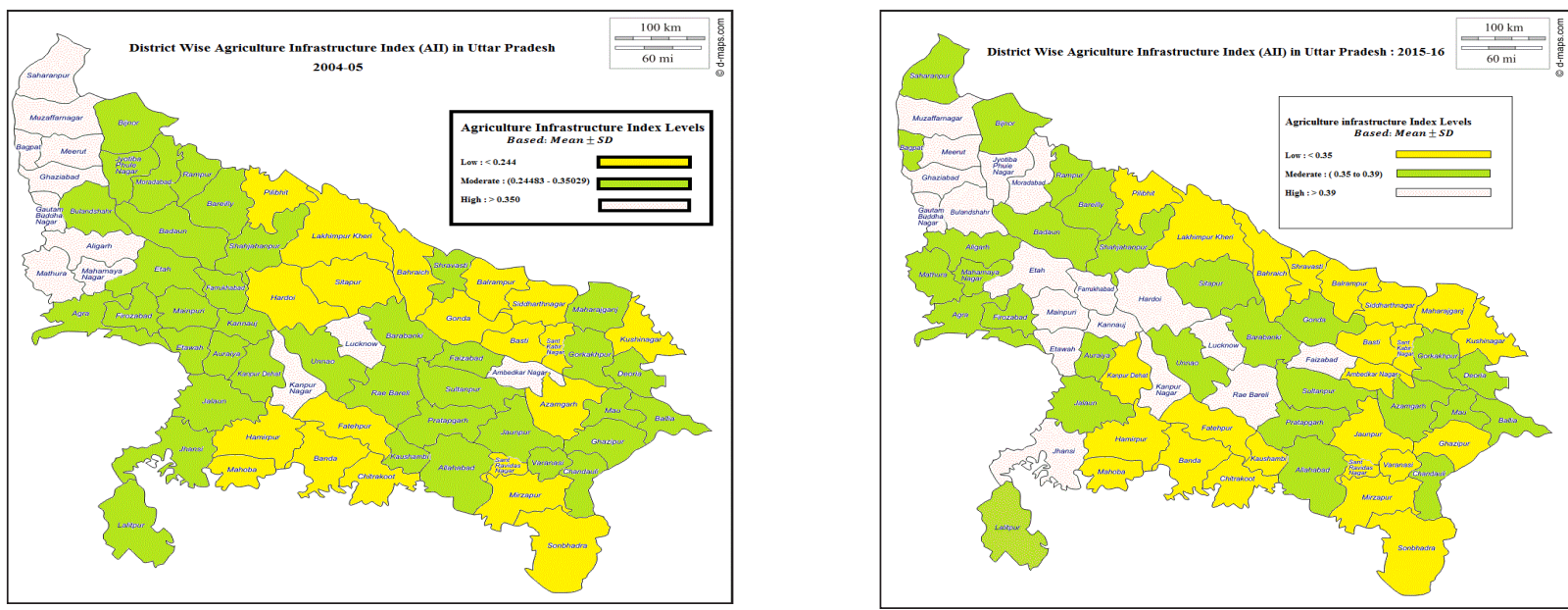

Map 1: District-Wise Comparison of Agriculture Infrastructural Index (AII) at 2004-05 and 2015-16

Sources: Map based on district wise level of Agriculture Infrastructure Index (AII) Value.

are very sharp variations in the AII levels across the district at state level during the study period. It is found that most of the districts of WUP fall in high degree of agricultural infrastructure in UP.

It is thus inferred that UP has shown tremendous growth in infrastructure from 2004-05 to 2015-16 with some minute fluctuations that has led to improvement in productivity and efficiency of the state. Thus, infrastructure can be said to be a precursor of development in agriculture.

\section{Trends of Agricultural Efficiency Index (AEI)}

The district levels as well as regional level trends of agricultural efficiency index (AEI) of Uttar Pradesh are shown in Table 3. It could be seen from the table that, the top 20 performers districts of AEI were found to be Shahjahanpur, Firozabad, Aligarh, GB Nagar, Haathras, Agra, Etawah, Farukhabad, Kaushambi, Fatehpur, Mainpuri, Baghpat, Jalaun, Rampur, Mathura, Meerut, Muzzaffarnagar, Bulandhshar, Ghaziabad and Pilibhit in 200405 while the bottom 20 ranks were taken up by Allahabad, Mau, Basti, Sant kabeer nagar, Sitapur, Deoria, Gorakhpur, Gajipur, Varansi, Gonda, Balrampur, Balia, Shravasti, Azamgarh, Hamirpur, Chandauli, Siddhratha nagar, Sant Ravidas Nagar, Mirzapur and Sonbhadra during the same period. However, if one compared the statistics in 201516, there were a few new entrants like Hardoi, Gajipur, Etah, Sant Ravidas Nagar, Auraiya, Jhansi, Kanpur Dehat, Kanpur Nagar indicating improved agriculture efficiency during the 12 year span of analysis. However, one also tends to witness new additions of few districts in the race of bottom 20 ranks as well like Jaunpur, Bareilly, Jalaun, Kushinagar, Fatehpur, Raebarelli, Unnao, Banda, Chitrakoot and Mahoba highlighting falling agriculture efficiency in $2015-16$ as compared to 2004-05.

However, with respect to administrative regions, it was found that the AEI rank of Bundelkhand was $3^{\text {rd }}$ in 2004-05 and slipped to $4^{\text {th }}$ in 2015-16. On the other hand, the AEI rank of Eastern region was $4^{\text {th }}$ in 2004-05 and moved to $3^{\text {rd }}$ in 2015-16 indicating to an increase in agricultural efficiency. In case of Central and Western regions, there was no significant change in AEI ranking during the study period.

Moreover, in terms of absolute values, Western UP topped in the list followed by Central UP while Bundelkhand and Eastern UP showed a mixed bag. It was observed that Eastern region improved AEI value in absolute terms as compared to the other regions while the absolute value of Bundelkhand region declined drastically in 2015-16.

Map 2 further shows the district-wise agriculture efficiency index obtained during the study period. The district wise agriculture efficiency index levels during the study period can be divided into three categories, namely, low: < 0.180 , moderate: $(0.180$ to 0.396$)$ and highest: $>0.396$.

The map shows that the agriculture efficiency index has wide spread variations across all districts during the study period at district level. It is also a 
Table 3: Trends of Agricultural Efficiency Index (AEI) and Rank at District Level

\begin{tabular}{|c|c|c|c|c|c|c|c|c|c|}
\hline \multicolumn{10}{|c|}{ District wise Ranking based on Agricultural Efficiency Index } \\
\hline \multirow{2}{*}{ Districts } & \multicolumn{2}{|c|}{ AEI Values } & \multicolumn{2}{|c|}{ AEI Rank } & \multirow{2}{*}{ Districts } & \multicolumn{2}{|c|}{ AEI Values } & \multicolumn{2}{|c|}{ AEI Rank } \\
\hline & 2004-05 & 2015-16 & 2004-05 & 2015-16 & & 2004-05 & $2015-16$ & 2004-05 & 2015-16 \\
\hline Agra & 122.88 & 109.97 & 6 & 26 & Jalaun & 117.53 & 93.50 & 13 & 55 \\
\hline Aligarh & 124.50 & 119.10 & 3 & 12 & Jaunpur & 93.64 & 94.72 & 42 & 51 \\
\hline Allahabad & 88.27 & 80.92 & 51 & 65 & Jhansi & 95.72 & 119.68 & 39 & 10 \\
\hline Ambedkar N & 93.25 & 105.95 & 44 & 31 & Kannauj & 103.03 & 97.74 & 28 & 48 \\
\hline Auraiya & 107.80 & 123.33 & 25 & 8 & Kanpur Dehat & 108.71 & 112.70 & 24 & 19 \\
\hline Azamgarh & 77.19 & 105.25 & 64 & 34 & Kanpur Nagar & 99.85 & 112.63 & 30 & 20 \\
\hline Baghpat & 117.95 & 119.39 & 12 & 11 & Kaushambi & 120.90 & 103.78 & 9 & 38 \\
\hline Bahraich & 88.76 & 96.01 & 48 & 50 & kheri & 89.83 & 110.24 & 47 & 25 \\
\hline Balia & 78.85 & 107.44 & 62 & 28 & Kushinagar & 101.85 & 89.91 & 29 & 58 \\
\hline Balrampur & 79.35 & 102.79 & 61 & 42 & Lalitpur & 97.67 & 81.42 & 33 & 63 \\
\hline Banda & 91.75 & 63.47 & 45 & 67 & Lucknow & 96.10 & 110.32 & 37 & 24 \\
\hline Barabanki & 105.76 & 102.69 & 26 & 43 & Maharajganj & 97.53 & 98.30 & 34 & 47 \\
\hline Bareilly & 88.41 & 94.03 & 50 & 53 & Mahoba & 88.65 & 32.52 & 49 & 70 \\
\hline Basti & 86.19 & 94.31 & 53 & 52 & Mainpuri & 119.43 & 136.93 & 11 & 2 \\
\hline Bijnor & 111.14 & 105.07 & 21 & 35 & Mathura & 116.61 & 125.35 & 15 & 7 \\
\hline Budaun & 96.03 & 103.64 & 38 & 40 & Mau & 86.31 & 103.71 & 52 & 39 \\
\hline Bulandhshar & 114.21 & 125.62 & 18 & 6 & Meerut & 116.49 & 116.21 & 16 & 14 \\
\hline Chandauli & 76.65 & 105.68 & 66 & 32 & Mirzapur & 69.34 & 97.12 & 69 & 49 \\
\hline Chitrakoot & 98.01 & 37.01 & 32 & 69 & Moradabad & 96.12 & 99.42 & 36 & 45 \\
\hline Deoria & 83.73 & 82.23 & 56 & 62 & Muzzaffarnagar & 115.44 & 115.53 & 17 & 16 \\
\hline Etah & 110.14 & 129.45 & 23 & 4 & Pilibhit & 113.12 & 112.38 & 20 & 21 \\
\hline Etawah & 121.65 & 117.76 & 7 & 13 & Pratapgarh & 90.19 & 100.96 & 46 & 44 \\
\hline Faizabad & 94.25 & 103.02 & 41 & 41 & Raebareli & 93.29 & 81.18 & 43 & 64 \\
\hline Farukhabad & 121.28 & 107.38 & 8 & 29 & Rampur & 116.65 & 110.88 & 14 & 23 \\
\hline Fatehpur & 120.85 & 86.32 & 10 & 59 & Saharanpur & 103.46 & 105.02 & 27 & 36 \\
\hline Firozabad & 125.40 & 113.40 & 2 & 18 & S. K. Nagar & 86.13 & 93.89 & 54 & 54 \\
\hline Gajipur & 82.83 & 130.21 & 58 & 3 & S. R. Nagar & 70.83 & 127.34 & 68 & 5 \\
\hline GB Nagar & 124.37 & 122.14 & 4 & 9 & Shahjahanpur & 129.57 & 99.34 & 1 & 46 \\
\hline Ghaziabad & 113.50 & 115.99 & 19 & 15 & Shravasti & 77.70 & 90.89 & 63 & 57 \\
\hline Gonda & 79.38 & 92.11 & 60 & 56 & Siddhratha N & 71.22 & 105.58 & 67 & 33 \\
\hline Gorakhpur & 83.08 & 83.85 & 57 & 60 & Sitapur & 85.26 & 110.91 & 55 & 22 \\
\hline Haathras & 123.34 & 113.88 & 5 & 17 & Sonbhadra & 53.89 & 83.51 & 70 & 61 \\
\hline Hamirpur & 77.14 & 59.00 & 65 & 68 & Sultanpur & 94.45 & 107.98 & 40 & 27 \\
\hline Hardoi & 110.39 & 138.56 & 22 & 1 & Unnao & 96.40 & 72.53 & 35 & 66 \\
\hline J.P. Nagar & 99.42 & 104.61 & 31 & 37 & Varansi & 82.72 & 106.97 & 59 & 30 \\
\hline
\end{tabular}

Administrative Region-wise Ranking based on Agricultural Efficiency Index

\begin{tabular}{|c|c|c|c|c|c|c|c|c|c|}
\hline \multirow{2}{*}{ Regions } & \multicolumn{2}{|c|}{ AEI Values } & \multicolumn{2}{|c|}{ AEI Rank } & \multirow{2}{*}{ Regions } & \multicolumn{2}{|c|}{ AEI Values } & \multicolumn{2}{|c|}{ AEI Rank } \\
\hline & 2004-05 & 2015-16 & 2004-05 & $2015-16$ & & 2004-05 & $2015-16$ & 2004-05 & 2015-16 \\
\hline Bundelkhand & 95.21 & 69.51 & 3 & 4 & Eastern & 84.76 & 99.79 & 4 & 3 \\
\hline Central & 100.64 & 103.81 & 2 & 2 & Western & 113.54 & 113.21 & 1 & 1 \\
\hline
\end{tabular}

Sources: Authors Calculations based on UPDES. 

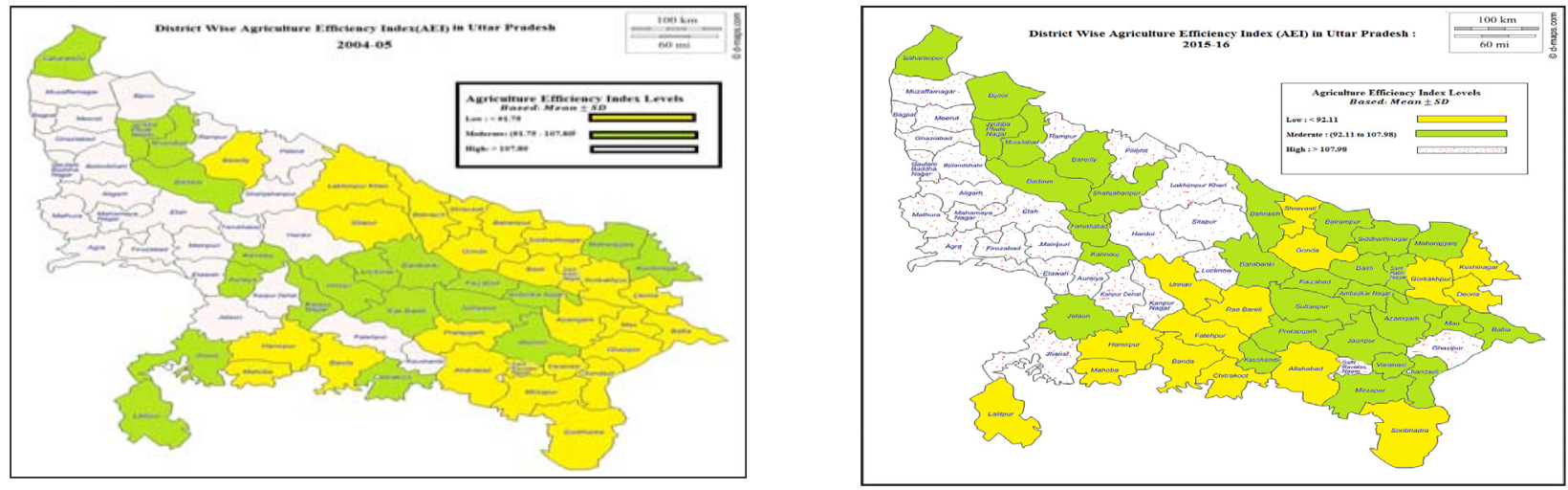

Map 2: District-Wise Comparison of Agriculture Efficiency Index (AEI) at 2004-05 and 2015-16

Sources: Map based on district wise level of Agriculture Efficiency Index (AEI) Value.

Table 4: Regression Results of Agricultural Efficiency Index (AEI)

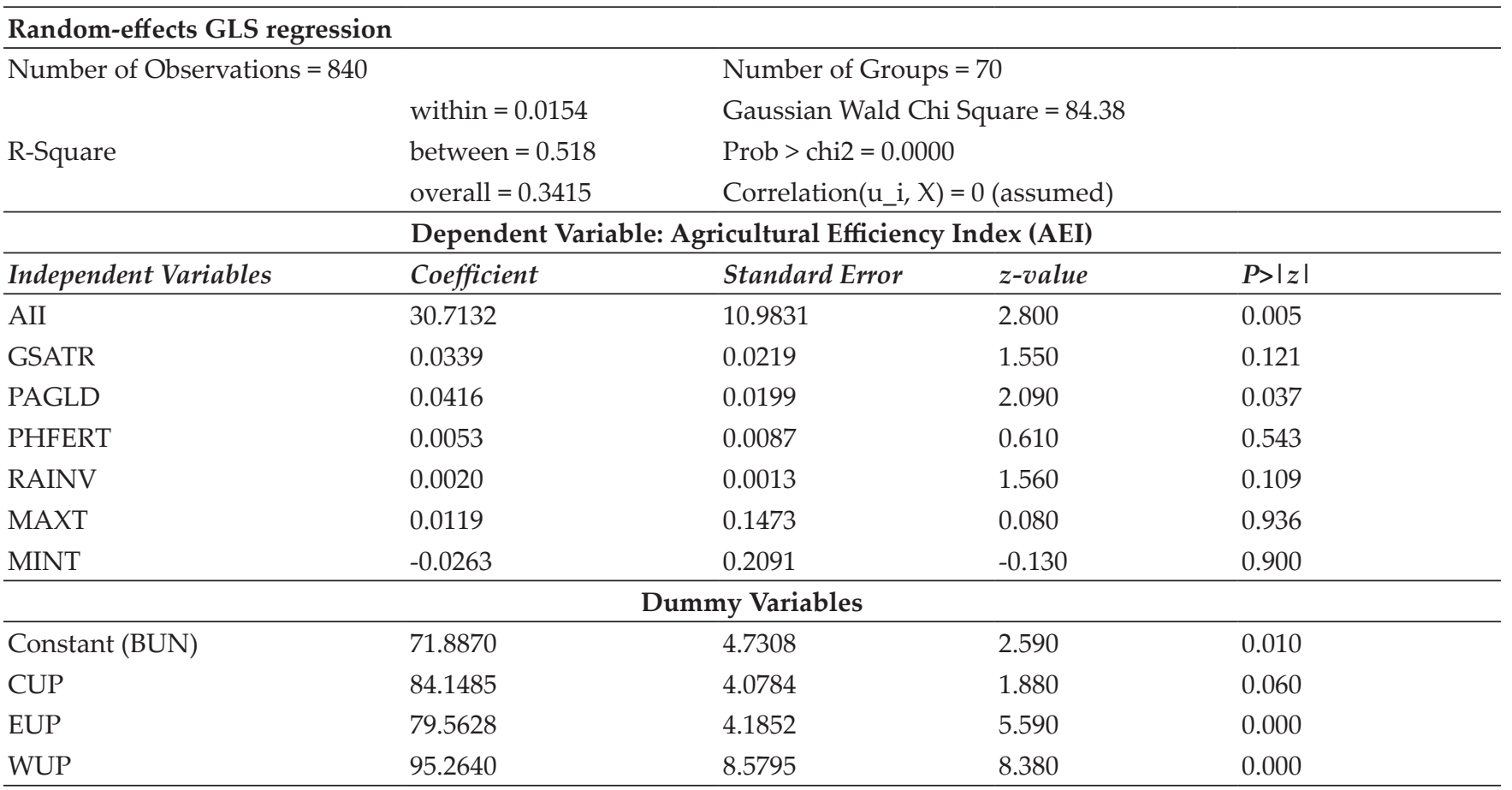

Hausman Test Result

$\mathrm{b}=$ consistent under Ho and Ha; obtained from xtreg

$\mathrm{B}=$ inconsistent under $\mathrm{Ha}$, efficient under Ho; obtained from xtreg

Test: Ho: difference in coefficients not systematic

chi2(6) $=(b-B)^{\prime}\left[\left(V_{-} b-V \_B\right)^{\wedge}(-1)\right](b-B)=9.79$

Prob $>$ chi $2=0.1337$

Thus, Random Effect Model is appropriate for the regression

Sources: Authors Calculations.

fact that there are very sharp variations in the AEI levels across the district and regional levels in UP during the study period. This clearly shows that performance of WUP has been marked by high degree of agriculture efficiency followed by CUP, EUP and Bundelkhand respectively over the 12 years span.

\section{Regression Result Discussion}

A further analysis through panel data regression was carried out in order to see the impact of various independent variables, viz. agricultural infrastructure, agricultural inputs and climatic factors on agricultural efficiency at district level in 
Uttar Pradesh. To recognize the drivers of agricultural efficiency index (AEI) in UP at disaggregate level, fixed and random effect models were used and to further choose an appropriate model, Hausman specification was adopted. The result of Hausman specification test revealed that the two models were not different enough to reject the null hypothesis. Hence, random effect model (REM) was applied to evaluate the drivers of agricultural efficiency index (AEI) at the district level for the study period and the result by using STATA are presented in Table 4 .

The random effect model (REM) reveals that the values of within, between and overall $\mathrm{R}$ - square are $0.0154,0.5180$ and 0.3415 respectively, which implies that the regression model on the whole explains more than 34 per cent per annum of the total variations in agricultural efficiency index. The magnitude of Wald Chi Square is very high and significant. It indicates that the given model is a good fit. The results of REM attest that Agriculture Infrastructure Index (AII), percentage of loan for agriculture to total loan (PAGLD), gross sown area per tractor (GSATR) and variability of rainfall (RAINV) have a statistically significant and positive impact on Agricultural Efficiency Index (AEI) throughout the study period. On the contrary, minimum temperature (MINT), per hectare fertilizer (PHFERT) and maximum temperature (MAXT) have insignificant impact on agricultural efficiency index.

The impact of Western Uttar Pradesh (WUP) as dummy variable on Agriculture Efficiency Index (AEI) is statistically significant and positive followed by Central Uttar Pradesh (CUP), Bundelkhand and Eastern Uttar Pradesh (EUP) in that order. Hence, the enhancement in agricultural infrastructure in terms of markets, rural roads, irrigation facilities, availability of electricity and agricultural credit societies is yet another domain that would help enlarge agricultural efficiency and productivity as well as reduce malnutrition and boost the livelihood security in Uttar Pradesh.

The regression results clearly demonstrate that most parameters of agriculture efficiency viz. agricultural infrastructure, agricultural inputs and climatic factors under consideration are found to influence the nature and the extent of agriculture efficiency in Uttar Pradesh at the district level during the study period in both ways. Some parameters have positive impact on agriculture efficiency and some have a negative impact on agriculture efficiency.

\section{CONCLUSIONS AND POLICY IMPLICATIONS}

The present paper has examined the emerging trends of agriculture efficiency and agricultural infrastructure in Uttar Pradesh at the district as well as regional level and identified the role of agricultural infrastructure, climatic factors and inputs in agriculture efficiency at disaggregated level. The extent of agriculture efficiency was found high in Western Uttar Pradesh; followed by Central Uttar Pradesh displaying moderate degree of agriculture efficiency while Eastern Uttar Pradesh and Bundelkhand registered low degree of agriculture efficiency. The same result was found in the case of agricultural infrastructure index as well. Within all the regions, sharp intra-regional disparities in case of agriculture productivity as well as agricultural infrastructure were found at both levels in Uttar Pradesh. Hence, appropriate agriculture policies should be one of the prerogatives of the Government to remove such disparities.

The regression results of random effect model however, revealed that agriculture infrastructure index, percentage of loan for agriculture sector, gross sown area per tractor, rainfall variability have a statistically significant and positive impact on agriculture efficiency index throughout the study period. On the other hand, minimum temperature, per hectare fertilizer and maximum temperature have statistically insignificant impact on agriculture efficiency in Uttar Pradesh at the disaggregate level.

Ergo, policy support measures in terms of enhanced agriculture infrastructure, appropriate use of agriculture inputs, mitigation of vulnerable climatic factors and suitable technology need to be extended to the farmers in the state enabling easy facilitation of generation of higher incomes via agricultural efficiency. Furthermore, the use of technological inventions by public--private participation in the improvement of cultivation methods for various crops can be another pivotal aspect to be encouraged for improving agriculture efficiency. In a nutshell, in order to achieve better efficiency of agricultural resources target based investments should be preferred by the government of the state. 


\section{ACKNOWLEDGEMENTS}

The authors acknowledge the funding support from ICAR-NIAP, New Delhi for Networking Project entitled "Structural Transformation, Regional Disparities and Institutional Reforms in Agriculture"

\section{REFERENCES}

Acharya, J., Govindaraju, K. and Gregory, S. 1992. Access to Infrastructure and Sustainability in Sericulture: A Study of Palani Taluk in Tamil Nadu. Bangalore: Institute for Social and Economic Change.

Agricultural Statistics at a Glance 2017. Directorate of Economics and statistics, Ministry of Agriculture \& Farmers Welfare, Government of India.

Bhatia, M.S. 1999. Rural infrastructure and Growth in Agriculture. Economic and Political Weekly, A43-A48.

Bhatia, S.S. 1967. A New Approach to Measure Agricultural Efficiency in Uttar Pradesh. Economics Geography, 43: 224-260.

Binswanger, H.P., Khandker, S.R. \& Rosenzweig, M.R. 1993. How infrastructure and financial institutions affect agricultural output and investment in India. Journal of Development Economics, 41(2): 337-366.

Chand, R. 2001. Emerging Trends and Issues in Public and Private Investments in Indian Agriculture: A State wise Analysis. Indian Journal of Agricultural Economics, 56(2): 161-84.

Fan, S., Fang, C. \& Zhang, X. 2001. How Agricultural Research Affects Urban Poverty in Developing Countries: The Case of China. Environment and Production Technology Division, IFPRI.

Fan, S., Hazell, P. and Thorat, S. 2000. Government Spending, Growth and Poverty in Rural India. American Journal of Agricultural Economics, 82(4): 1038-1051.

Hausman, Jerry A. 1978. Specification Tests in Econometrics. Econometrica, 46: 1251-1271.

Kendall, M.G. 1939. The Geographical Distribution of Crop Productivity in England. Journal of the Royal Statistical Society, 102, 1939 (New Series): 21

Kendall, M.G. 1939. The Geographical Distribution of Crop Productivity in England, Journal of the Royal Statistical Society, 52: 21-48.

Khandker, S. 1989. Improving Rural Wages in India. Policy, Planning, and Research Working Paper 276. Washington, D.C.: World Bank.
Khusro, A.M. 1964. Measurement of Productivity at Macro and Micro level, ibid, pp. 278.

Kurian, N. 2001. Regional Disparities in India. Retrieved March 5, 2011, Delhi: Planning Commission of India.

Mellor, J.W. 1976. The New Economics of Growth: Strategy for India and the Developing World, Cornell University Press, Ithaca, New York, USA.

Modi, V. 2005. Improving Electricity Services in Rural India. The Earth Institute at Columbia University, GSD Working Paper No.30, Columbia.

Nayak, C. 2008, Physical Infrastructure and Land Productivity: A District Level Analysis of Rural Orissa. The ICFAI University Journal of Infrastructure, 6(3): 7-21.

Nayak, C. 2014. Rural Infrastructure in Odisha: An Inter-District Analysis. PRAGATI: Journal of Indian Economy, 1(1): 17-38.

OECD 2008. Handbook on Constructing Composite Indicators, pp: 1-162, Paris: OECD Publishing

Parikh, K.S. 1999. India Development Report 1999-2000, Oxford University Press, UK.

Shafi, M. 1960. Measurement of Agricultural Efficiency in Uttar Pradesh. Economic Geography, 36: 296-305.

Sharma, J.S. 1965. Measurement of Agricultural Productivity: Concept, Definition etc. Journal of the Indian Society of Agricultural Statistics, 17(2): 253-257.

Singh, Jasbir 1979. A New Technique for Measuring Agricultural Efficiency in Haryana, The Geographer, 19(1): 14-33.

Spencer, D. 1994. Infrastructure and Technology Constraints to Agricultural Development in the Humid and Sub Humid Tropics of Africa. IFPRI, Environment and Production Technology Division, EPTD Discussion Paper No.3.

Thorat, S., Chand, R. and Bhalla, G. 2003. Rural Public Investment in India: Lessons for Growth and Poverty Reduction. New Delhi: International Food Policy Research Institute.

Verma, S., Ashok Gulati and Siraj Hussain 2017. Doubling Agricultural Growth in Uttar Pradesh: Sources and Drivers of Agricultural Growth and Policy Lessons", New Delhi: ICRIER, Working Paper 335.

World Bank 1997. Rural Development: Vision to Action: A Sector Strategy, The World Bank, Washington DC, USA. 